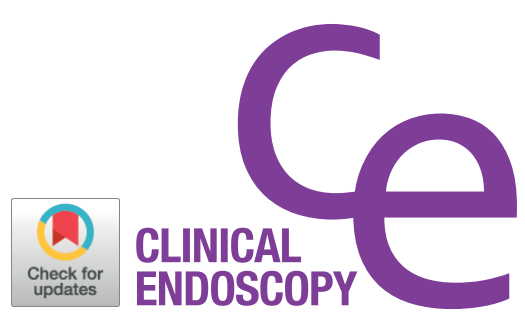

\title{
Nodular Lymphoid Hyperplasia with Aggressive Endoscopic Appearance in the Colon of an Adult Woman
}

\author{
Maria Fragaki ${ }^{1}$, Elpida Giannikaki ${ }^{2}$, Emmanouil Vardas ${ }^{1}$, Angeliki Theodoropoulou ${ }^{1}$, Aikaterini Tavernaraki ${ }^{1}$, Manousos \\ Christodoulakis $^{3}$ and Gregorios A. Paspatis ${ }^{1}$ \\ Departments of ${ }^{1}$ Gastroenterology, ${ }^{2}$ Pathology, and ${ }^{3}$ Surgery, Benizelion General Hospital, Heraklion, Greece
}

A 57-year-old woman with a history of arterial hypertension and appendectomy in childhood presented to the outpatient clinic, complaining of atypical abdominal pain and diarrhea that had persisted for 1 month. An abdominal computed tomography scan showed circular wall thickening in the ascending colon, as well as enlarged lymph nodes in the terminal ileum (Fig. 1).

Laboratory investigation results of hematological and biochemical parameters, as well as immunoglobulin levels, were all normal. Samples tested negative for the presence of hepatitis $\mathrm{A}, \mathrm{B}$, and $\mathrm{C}$ viruses, as well as for human immunodeficiency virus. Fecal sample also tested negative for bacteria and parasites. Upper gastrointestinal endoscopy was normal, and Helicobacter pylori infection was not identified.

Colonoscopy showed a protruding mass in the hepatic flexure (Supplementary Video 1, Fig. 2). The colonoscope could not be advanced beyond the ascending colon; as a result, complete colonoscopy could not be performed. Histological examination of multiple biopsies of the mass revealed that it had features similar to those of lymphoid lesions. The patient's clinical symptoms deteriorated and the intestine was almost completely obstructed; for this reason, a laparoscopic right hemicolectomy was performed. A macroscopic assessment of the surgical specimen revealed significant wall thickening

Received: February 20, 2016 Revised: March 20, 2016 Accepted: March 25, 2016

Correspondence: Gregorios A. Paspatis

Department of Gastroenterology, Benizelion General Hospital, L. Knossou, Heraklion 71409, Greece

Tel: +30-28-1036-8017, Fax: +30-28-1036-8018, E-mail: gpaspatis@gmail.com

(c) This is an Open Access article distributed under the terms of the Creative Commons Attribution Non-Commercial License (http://creativecommons.org/ licenses/by-nc/3.0) which permits unrestricted non-commercial use, distribution, and reproduction in any medium, provided the original work is properly cited.

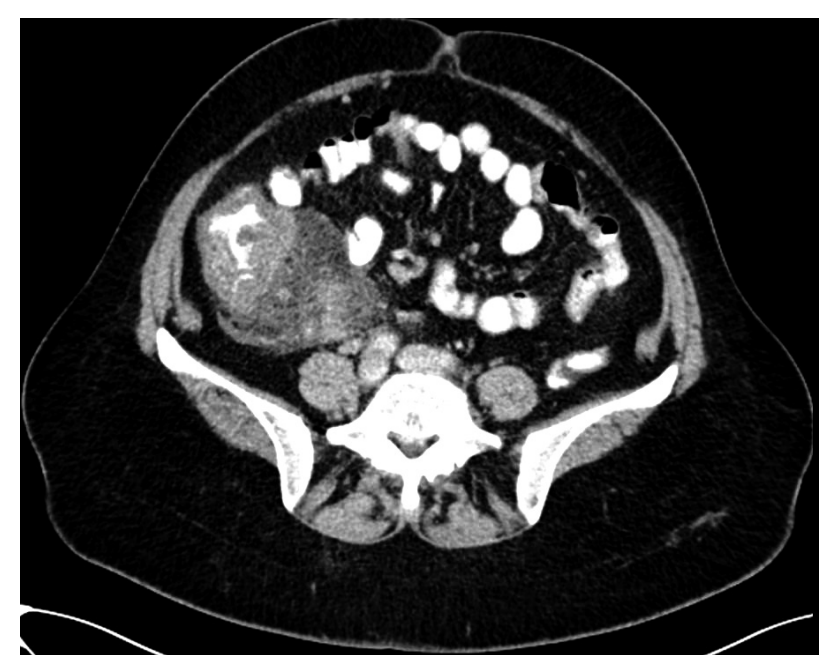

Fig. 1. Computed tomography scan showing circular wall thickening in the ascending colon, and the terminal ileum with enlarged lymph nodes.

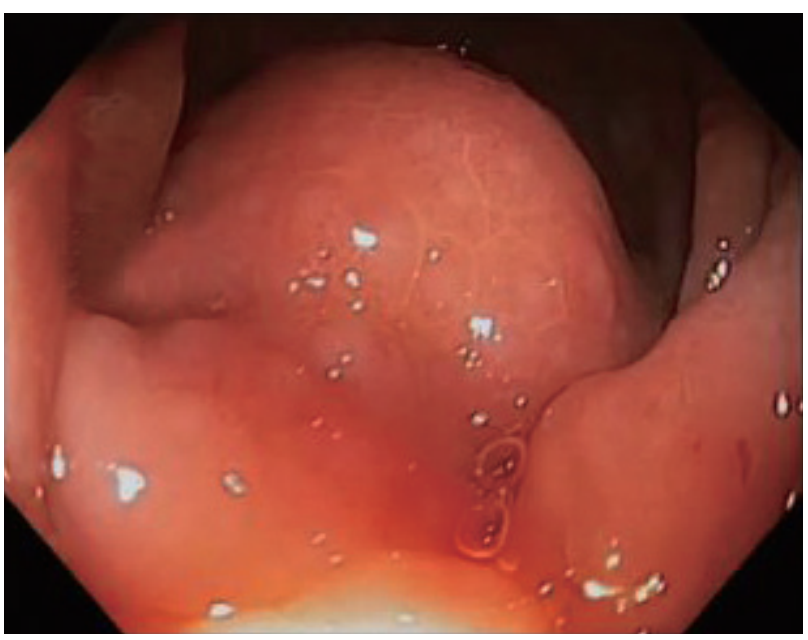

Fig. 2. Protruding mass in the hepatic flexure. 


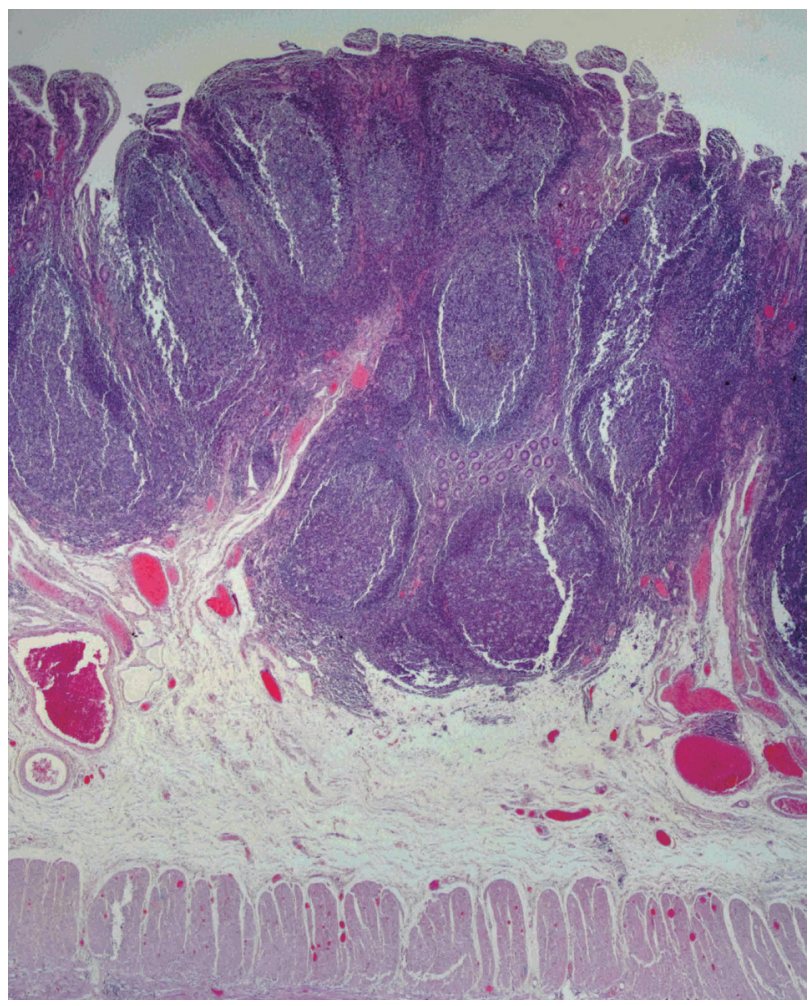

Fig. 3. Section from the cecum wall (H\&E stain, $\times 20)$, showing prominent lymphoid follicles, with highly reactive germinal centers, located in the mucosa and submucosa, suggesting nodular lymphoid hyperplasia.

in the ascending colon, cecum, and terminal ileum, as well as multiple mucosal nodules ( 1 to $7 \mathrm{~mm}$ ) in the same area; the nodules were partially fused together and occupied $2-\mathrm{cm}$ long area of the colon. A histology-based diagnosis of nodular lymphoid hyperplasia (NLH) of the terminal ileum and the colon was confirmed (Fig. 3). Furthermore, moderate chronic inflammation was detected, along with liponecrosis in the serosa. The patient did well post-operatively and since then has been free of symptoms.

Gastrointestinal NLH is characterized by the presence of multiple small nodules of 2 to $10 \mathrm{~mm}$ in diameter. ${ }^{1-3} \mathrm{It}$ primarily affects children, and it is usually asymptomatic; however, it may present with abdominal pain, chronic diarrhea, bleeding, or intestinal obstruction., ${ }^{1,4}$ The presentation of NLH in the right colon with an aggressive endoscopic, radiological, and clinical appearance without congenital or acquired immunodeficiency in an adult woman is a rare case.

\section{Conflicts of Interest}

The authors have no financial conflicts of interest.

\section{Supplementary Material}

Video 1. Nodular lymphoid hyperplasia in the colon (http://dx.doi. org/10.5946/ce.2016.041.v001).

\section{REFERENCES}

1. Albuquerque A. Nodular lymphoid hyperplasia in the gastrointestinal tract in adult patients: a review. World J Gastrointest Endosc 2014;6:534540.

2. Ranchod M, Lewin KJ, Dorfman RF. Lymphoid hyperplasia of the gastrointestinal tract. A study of 26 cases and review of the literature. Am J Surg Pathol 1978;2:383-400.

3. Rubio-Tapia A, Hernández-Calleros J, Trinidad-Hernández S, Uscanga L. Clinical characteristics of a group of adults with nodular lymphoid hyperplasia: a single center experience. World J Gastroenterol 2006;12:1945-1948.

4. Chandra S. Benign nodular lymphoid hyperplasia of colon: a report of two cases. Indian J Gastroenterol 2003;22:145-146. 